\title{
Climate dependence of silicate weathering intensity in East and Southeast Asia over the past 4 million years
}

FANGLIANG LI ${ }^{1,2}$, SHOUYE YANG ${ }^{1}$, ZONGQI DUAN $^{3,4}$ DAN BREECKER ${ }^{2}$, EVAN RAMOS ${ }^{2}$, XIANGTONG HUANG $^{1}$, YULONG GUO ${ }^{1}, \mathrm{CHAO} \mathrm{LI}^{1}$ AND XI MEI ${ }^{5}$

${ }^{1}$ Tongji University

${ }^{2}$ The University of Texas at Austin

${ }^{3}$ Institute of Geographic Sciences and Natural Resources

Research

${ }^{4}$ The Geographical Society of China

${ }^{5}$ Qingdao Institute of Marine Geology

Presenting Author: lif117@tongji.edu.cn

The negative feedback of silicate weathering is considered to play a key role in maintaining climate stability over geologic time. However, few studies have interrogated the climate dependence of silicate weathering intensity on a continental scale. Here weathering proxy records over the past 4 million years, mainly based on the Chemical Index of Alteration (CIA) data, are collected from 12 sites along the Asian continental margin, including a new core record in South Yellow Sea. All these records reveal a decrease in silicate weathering intensity since the late Pliocene, which occurs in the global context of cooling/drying climate and decreasing atmospheric $\mathrm{pCO}_{2}$. We stack regional CIA records and further show that the temporal decrease in weathering intensity in East Asia is greater than that in low-latitude Southeast Asia. The steepening of Pliocene-toQuaternary weathering gradient in East Asia coincides with the larger cooling trend in midlatitudes than in tropics, suggesting a sensitive weathering response to climate change across various latitudes. However, the potential provenance and weathering regime shift from a supply-limited pattern in proximal lowlands to a weathering-limited condition due to the expansion of sediment sources, might also influence the variations of weathering signals. This study sheds new light on the complicated linkage between continental weathering and global climate change. 